\title{
Bahasa Nasional dan Bahasa Lokal di Televisi Bagi Pembangunan Bangsa ${ }^{1}$
}

\author{
Endang K. Trijanto ${ }^{2}$
}

\begin{abstract}
Abstrak
Tulisan ini menyajikan upaya televisi nasional dan televisi lokal dalam menggunakan bahasa Indonesia dan bahasa lokal terkait dengan pembangunan bangsa. Bahasa yang dipergunakan di dalam tayangan televisi nasional atau TVRI pada umumnya adalah bahasa Indonesia, dan fokus amatan adalah tayangan budaya dalam dua bahasa, baik bahasa Indonesia maupun bahasa lokal atau bahasa daerah. Pada siaran televisi lokal, bahasa yang terutama digunakan adalah juga bahasa Indonesia, tetapi pada jamjam tayang tertentu digunakanlah bahasa daerah. Penggunaan dua bahasa ini di televisi dimaksudkan agar bahasa Indonesia dapat membangun dan meningkatkan cara berpikir bangsa Indonesia pada era global ini, serta untuk menjaga bahasa daerah dari ancaman kepunahan.
\end{abstract}

Kata kunci: bahasa Indonesia, bahasa daerah, televisi

\section{Pendahuluan}

Penggunaan bahasa nasional dan bahasa lokal di televisi adalah hal yang lumrah dan sudah umum ditayangkan di Indonesia. Akan tetapi, cara penyajian dua bahasa tersebut di televisi dan tujuan dilakukannya itulah yang akan diulas secara populer dalam tulisan ini. Alasan pengulasan secara populer karena penulis ingin mengajak pembaca untuk membahas hal yang sangat besar, yaitu pembangunan bangsa dengan cara sederhana, melalui tayangan yang kasat mata.

Tayangan di televisi nasional atau TVRI sebagian besar tayangannya menggunakan bahasa Indonesia, bahkan pada hari dan jam tertentu ada tayangan tentang "Pembinaan Bahasa Indonesia yang Benar". Untuk menonton tayangan dalam bahasa daerah, TVRI juga menyediakan jam tayang tertentu dan pada jam tayang tersebut selain digunakan bahasa daerah, juga ditunjukkan

\footnotetext{
${ }^{1}$ Pernah disajikan pada Seminar Internsional Bahasa dan Sastra dalam Konteks Kebangsaan (2010)

${ }^{2}$ Pengajar pada Universitas Negeri Jakarta
} 
keterkaitan antara bahasa daerah dengan budaya daerah. Sementara itu, televisi lokal, di antaranya Jak-tv untuk daerah Jakarta dan sekitarnya atau TV lokal lain untuk daerah tertentu dan sekitarnya, digunakanlah bahasa Indonesia dalam hampir semua tayangan serta bahasa daerah yang juga digunakan untuk menyiarkan berita lokal. Dari ulasan pendahuluan ini, yang menjadi fokus amatan penulis adalah upaya atau cara yang dilakukan televisi pada bahasa Indonesia dan bahasa daerah bagi pembangunan bangsa, serta tujuan melakukan hal itu.

\section{Pembahasan}

Untuk keperluan pembahasan, akan dicari terlebih dahulu definisi dari beberapa pengertian tentang bahasa nasional dan pembangunan bangsa, baik dalam bahasa Indonesia maupun dalam bahasa asing yang dikuasai penulis.

Dalam Kamus Besar Bahasa Indonesia (KBBI), dijelaskan bahwa bahasa adalah sistem lambang bunyi yang arbitrer, yang dipergunakan oleh para anggota suatu masyarakat untuk bekerja sama, berinteraksi, dan mengidentifikasikan diri. Bahasa nasional adalah bahasa yang menjadi bahasa standar atau lingua franca di negara yang mempunyai banyak bahasa karena perkembangan sejarah, kesepakatan bangsa, atau ketetapan perundangundangan. Dengan demikian, bahasa negara adalah bahasa resmi suatu negara. Bangun adalah bangkit. Pembangunan adalah proses, perbuatan, cara membangun. Bangsa adalah kesatuan orang-orang yang bersamaan asal keturunan, adat, bahasa, dan sejarahnya, serta berpemerintahan sendiri.

Dalam kamus besar bahasa Jerman (Wahrig), dijelaskan die Nation ist nach Abstammung, Sprache, Sitte, kultureller $u$. polit. Entwicklung zusammengehörige, innerhalb der gleichen Staatsgrenzen lebende, bewusst $u$. gewollt geformte politische Gemeinschaft (bangsa adalah kesesuaian asal, bahasa, adat istiadat, serta perkembangan budaya dan politik yang saling bersatu di dalam batas negara yang sama dan bersama-sama secara sadar mau membentuk kesatuan politik). National bedeutet eine Nation betreffend, ihr eigentümlich, ihr zugehörig, sie betonend (nasional berarti merujuk pada suatu bangsa yang menekankan pada milik bangsa itu dan termasuk di dalam bangsa itu), sedangkan die Bildung bedeutet (1) das Bilden, (2) Gestalt, Gesichtsschnitt, (3) Form (membangun adalah membentuk, keseluruhan, bagian muka, dan format). 
Dari dua kamus besar bahasa dalam satu bahasa tersebut, dapat disimak bahwa bahasa nasional adalah bahasa yang digunakan oleh seluruh rakyat di negara tertentu dan di Indonesia adalah bahasa Indonesia. Pembangunan bangsa adalah proses atau cara membangun bangsa yang berasal dari orang yang bersamaan keturunan, adat, bahasa, sejarah, dan berpemerintahan.

Selain pengertian di atas, perlu juga diulas beberapa pengertian terkait, misalnya televisi dan bagaimana televisi dapat mengupayakan bahasa serta budaya untuk membangun bangsa. Televisi sebagai bagian dari media massa adalah alat transmisi yang juga memberikan corak dan warna bagi penggunaan bahasa, yakni bahasa Indonesia dan bahasa daerah, serta budaya daerah. Keberagaman dan pengembangan kebudayaan melalui media massa/televisi berfungsi sebagai mediating dan shaping dalam membentuk wacana budaya. Selain itu, informasi, peristiwa, dan realitas yang terjadi telah dikonstruksikan (constructed of reality). Dengan demikian, wacana mengenai kejadian yang telah dikonstruksikan tersebut mengandung faktor internal dan eksternal, dalam hal ini kondisi sosial budaya.

Sementara itu, Kulturwissenschaften mengandung konsep kebahasaan dan kebudayaan. Dalam konsep kebahasaan terkandung "system of arbitrary vocal symbols by which members of a social group cooperate and interact." Dari "system of arbitrary vocal symbols", konsep kebahasaan atau linguistik mengacu pada keberkembangan secara teoretis, namun selanjutnya dari " $b y$ which members of a social group cooperate and interact" memunculkan pengertian sosiolinguistik yang sekaligus berkembang menjadi etnolinguistik, dan "Culture ... is that complex whole which includes knowledge, belief, art, morals, law, custom, and any other capabilities and habit acquired by man as member of society".

Dua konsep dasar ini kemudian memunculkan Vergemeinschaftung (pembentukan komunitas) dan Vergesellschaftung (pembentukan kemasyarakatan). Selanjutnya, konsep Weber "... the basis for community is a sense of belonging experienced by the participants, a feeling whose motivation is either affective or traditional". Dari konsep-konsep yang muncul dan saling melengkapi tersebut, dapat disarikan bahwa konsep bahasa sebagaimana juga konsep kebudayaan mengutamakan manusia sebagai warga masyarakat atau bangsa.

Terkait dengan analisis yang dilakukan dan mengacu pada peran bahasa yang berasal dari wacana di televisi baik nasional maupun lokal diperoleh: (1) 
4| Mabasan - Vol. 5, No. 2, Juli-Desember 2011

wacana dapat dianalisis dengan konsep kebahasaan, yaitu penggunaan bahasa Indonesia serta bahasa daerah (dalam hal ini bahasa Betawi); (2) demikian juga dengan konsep kebudayaan, yaitu ditonjolkannya budaya daerah di TVRI, dan budaya Betawi di Jak-TV; (3) Konsep kemasyarakatan yang terlibat dalam tayangan adalah masyarakat dengan bahasa Indonesia dan bahasa daerah yang tidak saja dipengaruhi realitas, tetapi bahasa juga mampu menciptakan realitas dan kebudayaan.

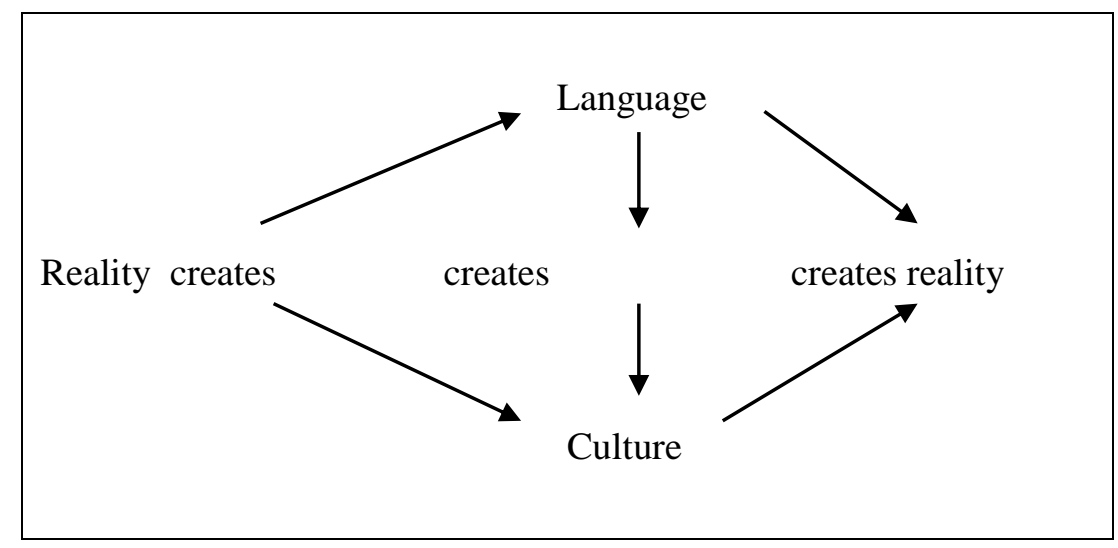

Gambar 1 : diadaptasi dari Ibnu Hamad, 2004:106

Manusia dalam segala kiprah dan kebudayaannya sangat memerlukan bahasa terutama untuk kepentingan-kepentingan pragmatis. Kehadiran teknologi komunikasi, di antaranya televisi nasional dan televisi lokal (khususnya TVRI) memiliki peranan yang sangat besar karena TVRI dapat diterima di mana pun di Indonesia. Menurut pendapat para pakar, TVRI dinamakan juga dengan TV-publik. Nama TV-publik diberikan kepada TVRI karena tayangan yang disiarkan diharapkan dapat diterima oleh publik, yaitu masyarakat Indonesia. Oleh karena itu, salah satu tayangan budaya yang disiarkan oleh TVRI diharapkan dapat diterima dan dinikmati oleh seluruh masyarakat di Indonesia, baik tua maupun muda. Harapan ini sesuai dengan fungsi televisi, yaitu sebagai media massa yang dilalui berbagai pesan dan informasi dengan bahasa pengantar bahasa Indonesia.

Kenikmatan dalam menonton tayangan budaya di TVRI sejak beberapa tahun terakhir sudah dirilis oleh pihak TVRI, tetapi sejak tahun 2009 tayangan budaya Indonesia menjadi semakin semarak saja. Jam-jam tayang dapat dikatakan cukup variatif dan program acara yang menayangkan budaya diantaranya, Pigura, Suku-Suku, Situs-Situs, Pesona Budaya Nusantara, Kisi- 
Kisi Budaya, dan Korpus Data yang kesemuanya merupakan tayangan budaya dari Pulau Sumatera, Jawa, Sulawesi, Nusa Tenggara Timur.

Berbagai analisis telah dilakukan. Selain analisis budaya, juga diterapkan analisis multikultur, begitu pula analisis bahasa dan kebahasaan. Artinya, bagaimana pembawa acara membawakan acara, cara bicara mupun mimik. Selain itu, analisis juga dilakukan dengan melihat teknik wawancara yang diterapkan, penggunaan bahasa daerah sebagai bantuan, dan penggunaan istilah bagi narasumber. Bagaimana pembawa acara berinteraksi dengan narasumber, ketepatan penggunaan tema dan rema, serta kohesi-koherensi sesuai kebutuhan juga menjadi bahan analisis. Hal yang lain adalah gaya bicara, yakni apakah si pembawa acara sambil berbicara juga menerangkan budaya (baik tari, nyanyi, atau tanda-tanda lain), serta wujud budaya setempat?

Metode yang digunakan adalah observasi (tidak berperan serta) dan multianalisis. Kedua metode ini digunakan karena tidak dapat dilakukan secara sendiri-sendiri dan terpisah-pisah. Pemaparan tentang hasil analisis data adalah sebagai berikut. Pertama, pembawa acara menceritakan (1a) kehidupan seniman tari topeng di Cirebon. Selain memaparkan kehidupan sehari-hari seniman juga tata cara seniman itu melatih muridnya menari topeng. Artinya, dalam menari topeng ada jenjang yang harus dilalui para murid. (1b) Masih di Cirebon, namun dalam tayangan yang berbeda hari dan waktu, yaitu budaya masyarakat di Keraton Kasepuhan dan Kanoman memandikan pusaka keraton. Ketaatan pada aturan dan tata cara masyarakat keraton atau penduduk di wilayah keraton mempersiapkan upacara/perhelatan, yaitu mereka mempersembahkan hasil bumi (padi, kelapa_-buah kelapa dan janur-, bumbu dapur, pisang), hasil ternak (ayam, kambing) dan membawanya ke keraton. Di keraton, para penduduk itu berbaris, berjalan sesuai aturan dan alur, laki-laki berjalan bersama laki-laki, dan perempuan berbaris sesuai alur, sebelum masuk area keraton mereka berganti pakaian dan mengenakan pakaian yang sesuai upacara. Dari desa yang jauh tersebut, masyarakat itu membawa hasil bumi dan ternak, kemudian di keraton sesuai dengan fungsinya mereka memasak barang yang dibawa, sebagai persiapan upacara. Di dalam keraton para putri, abdi dalem, dan petugas juga mempersiapkan upacara memandikan pusaka keraton. Upacara memandikan pusaka dipimpin oleh orang yang dituakan di keraton. (1c) Masih di Cirebon, cerita mistik seputar bangunan keraton.

(2) Kalimantan, lebih tepatnya di kota Banjarmasin. Kegiatan seharihari ibu rumah tangga daerah itu adalah juga mengerjakan pekerjaan rumah, 
6| Mabasan - Vol. 5, No. 2, Juli-Desember 2011

seperti memasak, berbelanja dan lain-lain. Untuk keperluan belanja, biasanya ibu-ibu pergi ke pasar. Di kota Banjarmasin yang urat nadi transportasinya adalah sungai, para pedagang menggunakan transportasi sungai, yaitu mereka menjajakan dagangan dengan naik perahu.

(3a) Sulawesi, Petani gula aren di Lalu'o, daerah Gorontalo. Pada tayangan ini pembawa acara sambil menceritakan letak dan kegiatan masyarakat di daerah itu, juga meliput kegiatan petani gula aren. Lahan pohon enau adalah lahan yang sudah lama dengan tata cara mendaras enau yang juga sudah kuno. Artinya, pohon-pohon enau tersebut sudah tua dan perlu peremajaan. Setelah air enau didapat, proses pembuatan gula aren dilakukan di suatu tempat. Setelah proses selesai, gula lalu dijual ke pasar. Bahasa yang digunakan untuk meliput, selain bahasa Indonesia juga bahasa daerah di Lalu'o untuk lebih menekankan arti ujaran. Berarti bahwa budaya itu memerlukan bahasa daerah untuk lebih menekankan dan memperjelas arti. Setelah itu, barulah bahasa Indonesia berperan. Dengan demikian, bahasa Indonesia digunakan untuk menjembatani bahasa daerah dan budaya daerah. (3b) Masih di Sulawesi, tepatnya Manado. Kehidupan sehari-hari masyarakat adalah melaut, baru-baru ini kota Manado juga menjadi penerima tamu untuk merayakan acaraacara kelautan. (3c) Salah satu kerajaan dekat Pulau Buton, di Bau-Bau. Tayangan budaya yang ditampilkan adalah sebuah benteng yang didirikan pada abad 15. Sampai kini benteng itu masih berdiri dan utuh dengan segala kehidupan masa lalu dan masa kini.

(4a) Sumatera, pembangunan kembali Istano Basa Pagaruyung yang terbakar tahun 2007. Pembangunan kembali dimulai tahun 2008, direncanakan selesai tahun 2009, dan diresmikan awal tahun 2010. Budaya yang ditayangkan adalah tata cara membangun istana yang terbakar tersebut dengan budaya Minang. Para pekerja berasal dari daerah sekitar istana, kecuali para tukang ukir. Meskipun tidak berasal dari sekitar Pagaruyung, namun mereka adalah seniman ukir dari Minang. Hal itu dilakukan karena kegiatan mengukir memerlukan keahlian khusus. (4b) Daerah Jambi, yaitu panen ikan di Lubuk Larangan. Tayangan adalah tata cara masyarakat di sekitar Lubuk Larangan ketika memanen ikan. Acara ini dilakukan dua tahun sekali karena selama itu ikan dikembangkan untuk dapat dipanen. Panen dilakukan ketika sudah waktunya, kemudian persiapan panen dilakukan dengan cara membuat penghalang atau rintangan secara melintang untuk membendung sungai atau lubuk. Dengan demikian, ikan tidak akan lari sehingga lebih mudah ditangkap. 
Sejumlah orang juga secara bersama-sama membuat alat penangkap ikan bubu yang besar sekali. Pada hari yang ditentukan, upacara dimulai dengan menyanyikan lagu-lagu penghantar dengan iringan tabuhan musik. Cara memanen ikan juga beragam, ada ikan yang ditangkap dengan tangan saja atau dengan menebar jala. Terakhir, menggunakan bubu raksasa, yaitu dengan cara menggiring ikan ke hulu sungai/lubuk. Setelah semua ditangkap dan dikumpulkan, ikan kemudian dimasak atau dibakar dan dibagikan pada semua orang, lalu dimakan bersama.

Dari daerah (1) sampai dengan (4), tayangan budaya tersebut ditandai dengan berbagai hal berikut: a) harus ada kerja sama - (1a) seniman tidak dapat bekerja sendiri, ia memerlukan murid agar tariannya eksis. Selain murid, juga penabuh gamelan; (1b) upacara memandikan pusaka keraton diperlukan bantuan penduduk untuk menyelesaikan berbagai pekerjaan, (2) pedagang dan ibu rumah tangga perlu bekerja sama agar dagangan laku dan habis terjual, (3) petani gula aren di Lalu'o serta pelaut di Manado perlu kerja sama agar pekerjaannya berhasil dengan baik, juga dengan masih hadirnya benteng yang pada masa lalu menjadi andalan masanya, dan (4) membangun kembali Istana Pagaruyung dan memanen ikan di Lubuk Larangan/Jambi juga memerlukan kerja sama agar hasil kerja dapat dinikmati bersama. Berarti bahwa dibalik tayangan budaya tersebut, ternyata yang ingin diutarakan adalah kebermaknaan dari kerja sama.

(5) Daerah Jawa, tayangan adalah cuplikan dari pewayangan, yaitu perang antara Bismo dan Srikandi. Agak berbeda dari makna budaya sebelum ini, makna yang ingin ditonjolkan adalah kepatuhan dan keutamaan tata krama. Bahasa daerah/bahasa Jawa yang digunakan adalah bahasa Jawa tingkat tinggi, yaitu bahasa Jawa Kromo Inggil. Hal itu semakin memperjelas makna kepatuhan dan keutamaan kesatria.

(6) Daerah Nusa Tenggara Timur/NTT. Tayangan budaya adalah tata cara menangkap ikan di laut kemudian hasil tangkapan diolah secara tradisional. Jadi, tata cara mengolah ikan yang akan dijual ke pasar. Yang ditonjolkan di sini adalah wujud budaya, yaitu wujud budaya mata pencaharian, selain sebagai nelayan, tukang masak ikan, kemudian cara pemasaran makanan atau istilah modern adalah marketing. Jadi, makna yang dikandung adalah kegiatan mandiri, yang dikombinasikan dengan bekerja sama.

(7) Daerah paling selatan di NKRI. Daerah ini menampilkan budaya upacara bendera pada hari kemerdekaan RI. Meskipun seluruh daerah di NKRI 


\section{8| Mabasan - Vol. 5, No. 2, Juli-Desember 2011}

juga menampilkan upacara bendera pada hari Kemerdekaan RI tanggal 17 Agustus 2009, daerah ini termasuk daerah yang istimewa karena letaknya paling selatan dari seluruh daerah di Indonesia.

(8) Minggu Malam Bersama Slamet Rahardjo, adalah tayangan di TVRI pada setiap hari Minggu malam.

Dari tayangan-tayangan budaya (1) - (8), dapat dilakukan pemilahan berikut. Secara ontologis, budaya adalah kehidupan sehari-hari dari masyarakat (1a, 1b, 1c) sampai dengan (8), yakni mulai dari bangun tidur, berkegiatan, sampai dengan tidur lagi pada malam hari. Kegiatan itu dapat terjadi di kota, desa, pedalaman, pesisir, maupun gunung. Asal budaya itu dari pulau atau daerah paling barat, bagian tengah, timur, utara, dan selatan.

Kegiatan sehari-hari (1a) dari seniman adalah melatih tari topeng dan mengupayakan peralatan tari dan tabuhan. (1b) Melakukan persiapan untuk menghadap raja dalam rangka perhelatan/upacara memandikan pusaka keraton, yaitu dengan cara menyiapkan bahan makanan (padi, kelapa, ternak), minuman (melalui alat pengambil air), membawa peralatan upacara (janur, daun pandan, kembang setaman). (1c) Bangunan keraton, dengan mengenali kekuatan mistik dari keraton, baik Kanoman maupun Kasepuhan.

(2) Budaya pedagang di Samarinda yang menggunakan perahu sebagai modal transportasi sungai, sekaligus modal untuk mencari nafkah.

(3) Di Sulawesi, (3a) budaya mendaras pohon enau. Dengan pohon enau yang sudah tua dan sangat tinggi, hasil yang diperoleh juga tidak maksimal. Pemanjat pohon yang berusia muda untuk memanjat pohon tinggi pun semakin langka. Setelah air diperoleh kemudian diangkut dengan bambu ke tempat pengolahan, air enau dimasak dan diproses untuk menjadi gula aren. Setelah proses pembuatan selesai, aren dibawa untuk dijual ke pasar. (3b) dan (3c) budaya yang ada di dalam benteng dengan 12 (dua belas) lubang pintu itu sudah berlangsung sejak zaman dulu dan perubahan hanya pada bentuk pemerintahan sebagaimana daerah lain di Indonesia.

(4a) Budaya membangun istana diusahakan sama dengan tata cara membangun istana dengan gaya Minang pada masa lalu. Pembangunan pada masa kini sama dengan masa lalu. (4b) budaya menangkap ikan dilakukan dengan tata cara yang sudah dilakukan orang pada masa lalu, yaitu dengan cara bekerja sama dan berbagi hasil dari apa yang diperoleh.

Budaya (5) sampai (8) secara ontologis juga menampilkan keunggulan asalnya. 
Setelah pembahasan asal budaya, perlu juga wujud budaya, antara lain mata pencaharian. (1) Wujud mata pencaharian adalah seniman, petani, peternak dan priyayi. (2) Bagi warga Samarinda, mata pencaharian yang menggunakan perahu biasanya adalah pedagang. (3) Selain petani, yaitu petani pohon enau, juga pelaut dan penyelam, serta pegawai di benteng. (4) Tujuan tayangan budaya di Istano Basa Pagaruyung adalah menampilkan wujud budaya yang bermata pencaharian tukang bangunan khas Minangkabau, baik tukang kayu, juga tukang kriya ukir. Di Jawa (6) adalah seniman wayang orang,

Secara epistemologis dapat dirunut upaya yang dilakukan oleh stasiun TV Daerah dalam memproduksi tayangan budaya untuk disiarkan TVRINasional di Jakarta. Salah satu cara, yaitu dengan menggunakan bahasa pengantar bahasa Indonesia. Contoh tayangan tersebut yaitu, Situs-Situs, SukuSuku, Pigura, dan Pesona Budaya Nusantara. Waktu penayangan adalah hari Senin sampai dengan Sabtu, sekitar pukul 6.30 hingga pukul 7.00 WIB atau kadang-kadang pada sore hari atau bahkan pada malam hari.

Tayangan (1) sampai (8) dianalisis dengan mengadaptasi model analisis Klaus R. Wagner. Hal itu dilakukan karena selain menganalisis budaya juga dilihat keterkaitan pewawancara dengan budaya dan objek bahasan

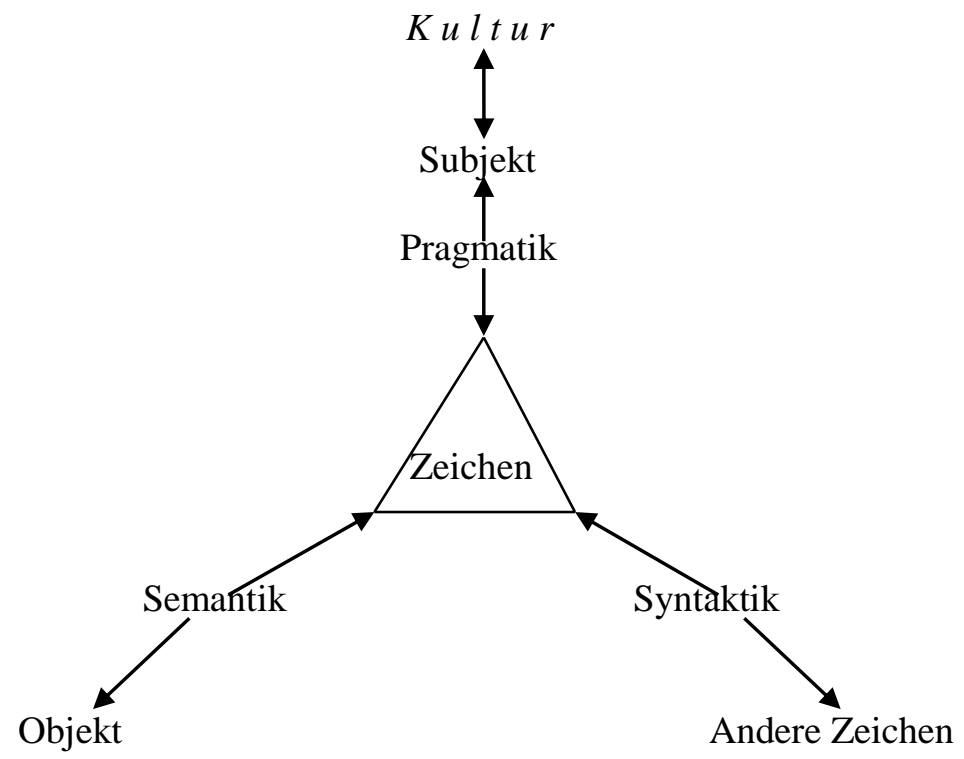

Gambar : diadaptasi dari Klaus R. Wagner, 2001 
Rata-rata pewawancara dapat menggunakan bahasa daerah dari budaya yang didekatinya. Penggunaan bahasa daerah akan diterjemahkan ke dalam bahasa Indonesia untuk memperjelas komunikasi dan interaksi yang terjadi.

Cara bicara disertai gestik dan mimik juga mewarnai penayangan budaya untuk memperlengkap informasi yang disampaikan. Contoh (1b) masyarakat yang datang berduyun-duyun dan berjalan secara tertib menuju keraton di Cirebon. (2) Interaksi pewawancara dengan ibu-ibu pedagang yang menggunakan perahu sebagai modal transportasi air di Banjarmasin. (3c) Mewawancarai petugas di benteng yang mempunyai pintu atau lawang sebanyak dua belas buah untuk ke luar dan masuk benteng. Teknik wawancara yang digunakan adalah wawancara terbuka untuk memancing narasumber menceritakan budaya daerah itu. Meskipun begitu, teknik wawancara tertutup juga digunakan seperlunya.

Penggunaan tema-rema, kohesi-koherensi dalam bahasa daerah yang diterjemahkan ke dalam bahasa Indonesia juga mewarnai tayangan budaya ini. Musik penyerta dari budaya setempat kadang-kadang cukup mengganggu karena nada yang monoton dan disetel cukup keras dalam pemberitaan. Selingan humor juga ditampilkan oleh pembawa acara dalam tayangan. Contohnya, pembawa acara ikut tercebur di Sungai/Lubuk Larangan ketika ikut menunjukkan cara menangkap ikan.

Secara epistemologis, tayangan budaya (1)_-(8) telah ditampilkan secara variatif. Dengan demikian, diharapkan cara penyampaian tersebut akan mengenai sasaran TV-publik, yaitu memberi informasi secara apa adanya/otentik, tetapi informasi tersebut masih dapat menghibur penonton.

Sisi aksiologis sebagaimana diharapkan, TVRI telah menayangkan beragam budaya daerah di Indonesia dalam bahasa Indonesia dan dibumbui bahasa daerah. Diharapkan masyarakat atau bangsa Indonesia, dapat memahami ragam budaya daerah lain di luar daerahnya sendiri, serta tidak menghadapinya sebagai suatu yang stereotip. Dengan begitu, semua terikat dalam bingkai Bhineka Tunggal Ika atau keragaman budaya dan bahasa yang mempersatukan serta membangun bangsa.

\section{Penutup}

Melalui tayangan budaya daerah dan bahasa daerah baik di TVRI maupun TV local, diharapkan kesadaran berbahasa Indonesia dan berbahasa daerah semakin tumbuh. Melalui bahasa Indonesia, diharapkan bangsa 
Indonesia menggunakan bahasa Indonesia sebagai sarana menghadapi era global untuk berkomunikasi maupun memecahkan masalah. Pembahasan dalam tulisan ini dari sisi budaya daerah karena fokus amatan penulis adalah pada keberlangsungan budaya dan bahasa daerah. Hal dilakukan agar bahasa daerah atau bahasa lokal tidak menjadi punah. Bahasa Indonesia juga perlu dijaga kelestariannya sebagai bahasa nasional dan bahasa Negara.

\section{DAFTAR PUSTAKA}

Deddy Mulyana dan Jalaluddin Rakhmat. 2003. Komunikasi Antarbudaya. Bandung: Remaja Rosdakarya.

E.K.M. Masinambow. 2000. "Linguistik dalam Konteks Studi Sosial-Budaya" dalam Kajian Serba Linguistik. Bambang Kaswanti Purwo (ed). Jakarta: Gunung Mulia.

Endang K. Trijanto. 2008a. "Wacana Lisan Singkat di Media Elektronik sebagai Perekat Budaya" dalam Seminar Antarbangsa Linguistik \& Pembudayaan Bahasa Melayu ke-4. Kuala Lumpur: Universiti Putra Malaysia, tanggal 11-12 November 2008.

Endang K. Trijanto. 2008b. Bahasa Jawa Dialek Surabaya Warisan Jati Diri Masa Lalu, Kini, dan Kelak. Makalah disajikan di Universiti Brunei Darussalam, Januari 2008.

Endang K. Trijanto. 2009. Metodologi Penelitian. Yogyakarta: Pustaka.

Hamad, Ibnu. 2004. "Bahasa, Kebudayaan, Media dan Analisis Wacana" dalam KOLITA-2. Katharina Endriati Sukamto (ed). Jakarta: Unika Atma Jaya.

Klaus R. Wagner. 2001. Pragmatik der deutschen Sprache. Frankfurt am Main: Peter Lang GmbH.

Lilawati Kurnia. 2005. “Mengapa Multikulturalisme?” Dalam Publikationsreihe Klee-Blätter der Jurusan Sastra Jerman UNPAD. hh. $35-41$.

Marijana Kresic. 2006. Sprache, Sprechen und Identität. München: IUDICIUM Verlag. 
12| Mabasan - Vol. 5, No. 2, Juli-Desember 2011

Renate Wahrig-Burfeind (Hrsg). 2006. Wahrig: Deutsches Wörterbuch. Gütersloh - München: Wissen Media Verlag, GmbH. h. 1055.

Tim Redaksi. 2000. Kamus Besar Bahasa Indonesia: Edisi Kedua. Jakarta: Balai Pustaka.

TVRI. 2009. http://www.suarakarya-online.com/news.html diunduh 10 Juni 2009

Marijana Kresic. 2006. Sprache, Sprechen und Identität. München: IUDICIUM Verlag.

Klaus R. Wagner. 2001. Pragmatik der deutschen Sprache. Frankfurt am Main: Peter Lang GmbH. 